\title{
Acceptability And Feasibility of a Gamified Digital Eating Disorder Selective Prevention Program (AcceptME) Based On Acceptance And Commitment Therapy (ACT)
}

\section{Patrisia Nikolaou}

University of Cyprus: Panepistemio Kyprou

Rhonda M. Merwin

Duke University

Maria Karekla ( $\square$ mkarekla@ucy.ac.cy)

University of Cyprus: Panepistemio Kyprou https://orcid.org/0000-0001-7021-7908

\section{Research Article}

Keywords: Gamification, Digital Intervention, Acceptance and Commitment Therapy, Selective Prevention, High-risk for Eating Disorders, Vicarious learning

Posted Date: September 15th, 2021

DOl: https://doi.org/10.21203/rs.3.rs-871736/v1

License: (c) (1) This work is licensed under a Creative Commons Attribution 4.0 International License.

Read Full License 


\section{Abstract}

Background: Digital prevention programs for a variety of psychological conditions, including eating disorders (EDs) are increasing. Yet, none to date have leveraged gamification and vicarious learning components grounded in empirically-supported therapeutic approaches to engage young people at risk for developing EDs in behavior change. The current paper describes the development and preliminary acceptability and feasibility testing of AcceptME, a novel self-directed, gamified digital ED selective prevention program based on Acceptance and Commitment Therapy (ACT). AcceptME helps women and girls identified at risk for an ED relate differently to their thoughts and feelings, such that these experiences do not have undue influence over their behavior and actions can instead be guided by personal values.

Methods: Users learned skills of psychological flexibility by helping a third-person avatar (a main character in a storyline) navigate situations that elicit distressing thoughts/feelings, and via interactive exercises, practiced applying these skills to their own experiences. Young women and girls in the Republic of Cyprus with high weight concern scores $(\mathrm{N}=58$, Mage=15.27, $S D=2.25)$ completed six 30-minute digital sessions and reported on session and intervention acceptability.

Results: Attrition was $35.42 \%$. The majority of participants were either "Very" (40\%) or "Mostly" (57\%) Satisfied with the program. Fifty-two percent reported that the program "Helped a lot," and $48 \%$ said it "Helped a bit."

Conclusion: Digital technology and gamification have advantages for engagement and delivery. The current study suggests a promising direction for early ED interventions to reach at risk youth and preliminary data to guide development.

\section{Plain English Summary}

No prevention programs to date have utilized gamification and vicarious learning components grounded in empirically-supported therapeutic approaches for the prevention of eating disorders. This paper describes the development and preliminary acceptability and feasibility testing of AcceptME, a novel selfdirected, gamified digital ED selective prevention program based on Acceptance and Commitment Therapy (ACT). AcceptME helps women and girls identified at risk for an ED relate differently to their thoughts and feelings, such that these experiences do not have undue influence over their behavior and actions. Most participants were "Very" or "Mostly" satisfied with the program and felt "Helped a lot," by it.

\section{Background}

Eating Disorders (EDs) result in numerous physical and psychological adverse consequences for a suffering individual and their family. Yet, population-based studies of EDs indicate that only $20 \%$ of adolescents seek treatment and mostly seek treatment once they are severely impaired (1). The infrequent treatment seeking from adolescents is associated with feelings of shame and stigma, concern 
for others, self -sufficiency, fear of losing control (2), and failure to perceive the severity of the illness (1). Digital intervention programs may help overcome such barriers-to-treatment as they provide intervention in a safe environment and can be anonymous, thus circumventing fears of disclosure or being judged (3). As digital interventions can minimize feelings of exposure and shame, it may be easier to engage and complete exercises, explore and express difficult thoughts and feelings (e.g., body dissatisfaction), and consider behaviour change (3). Such programs also remove geographical constraints, allowing individuals even from remote locations to get support, and can be available 24 hours a day and 7 days per week (Karekla \& Savvides, 2019).

As youth are especially attracted to digital and smartphone multimedia applications, there is a growing recognition that digital gamification prevention programs may be the preferred delivery method to reach this age group (5). Gamification is the integration of game design elements (such as animations, videos and point reward systems for exercise and game completion) into prevention programs (6). Many gamification features are grounded in behavior change theory and utilize operant learning principles with demonstrated behaviour change effectiveness (e.g., reinforcement; Deterding et al., 2011). Gamification also includes the use of a storyline (7), which involves a compelling narrative with clear rules, challenging and achievable goals. Storytelling is an established method to purposefully learn from another's experiential knowledge (8) and is perceived as pleasurable (9). It can provide the opportunity to observe the intervention skills and techniques in practice, rather than receiving didactic instruction or just reading "dry facts" (10) and it can engage the person more deeply and experientially, with the possibility of greater long-term learning impact (Karekla et al., 2019). In addition, vicariously learning through storytelling can help improve understanding of difficult-to-grasp therapeutic concepts, (12), and provide relatable, real-life examples of skill use that may be imitated in the future. The perspective from which a desired behaviour is observed can be significant in determining whether they are motivated to consequently execute that behaviour themselves (13). Visualizing a task from a third-person perspective can result in more abstract understanding which leads to perceiving the behaviour as more important (13) and motivates health behaviour changes (14).

Preliminary evidence suggests that gamification can improve participants' health behaviours in areas such as addiction, healthy eating, physical activity, physical therapy, smoking cessation, cancer treatment adherence and self-management of asthma and diabetes (Johnson et al., 2016; Karekla et al., 2019). However, the application of gamification components for behaviour change is still in its infancy (Karekla et al., 2019). To date, ED prevention programs have not utilized gamification, storyline and vicarious learning principles to engage young people at risk for an ED and facilitate behaviour change.

Digital interventions that include gamification are more effective if they are developed based on a sound psychological theory of change (Loucas et al., 2014; Karekla et al., 2019). Existing ED prevention programs have aimed to decrease ED risk by either reducing the pursuit of the thin ideal (Stice et al., 2013; Stice et al., 2019) or on disputing and replacing unrealistic thoughts with regard to food, body and weight (19). This approach, based on traditional cognitive-behavioral therapy (CBT), has been helpful, but effects are modest, and Stice and other experts have called for additional ED prevention programs targeting other 
mechanisms of ED development (18). Contemporary CBTs (such as Acceptance and Commitment Therapy; ACT; Hayes et al., 2012) offer an alternative approach, targeting the function of ED symptoms, rather than their topographical form. There is a long history of evidence suggesting that ED symptomatology and control of emotional states either by avoiding or inhibiting emotional responses (Cockell et al., 2004; Heatherton \& Baumeister, 1991; Koushiou et al., 2018; Merwin et al., 2011, 2013). Changing how individuals relate or respond to internal experiences, and decoupling the functional relationship between these internal experiences and maladaptive control behaviors (26) may apply across time and situations, and allow for more immediate and long-lasting behaviour change (Juarascio et al., 2013; Merwin \& Wilson, 2009).

Acceptance and Commitment Therapy (ACT; (Hayes, Strosahl \& Wilson, 1999) is a functionalcontextualistic CBT that explicitly targets experiential avoidance and control strategies that underlie a range of psychological problems. According to ACT, the content of internal experiences is mainly outside voluntary control and therapy should focus on teaching patients to become more accepting of unwanted internal thoughts and feelings (20). ACT interventions allow individuals to have internal experiences (including distressing thoughts and feelings about the body) while pursuing personal meaningful values (30). The aim is for behavior to be less unduly influenced by these experiences and more flexible and effective; matched to the individual's ongoing and dynamic needs (e.g., signals of hunger/satiety, emotions; Merwin et al., 2011). Thus, individuals may have negative thoughts and feelings about the body, or feelings of anxiety and guilt, and still treat their body well (e.g., eating to hunger/satiety, not purging or engaging in other maladaptive weight control strategies) if doing so aligns with their personal values (31-34). Individuals vulnerable to an ED develop increasing preoccupation with body shape and weight and control over eating (35), often losing sight of other things that are important to them, and contributing to ambivalent feelings towards engaging into treatment. A prevention program based on ACT has the potential to assist high risk individuals by clarifying personal values in other life domains and facilitating a desire to change. ACT holds potential in improving outcomes in ED treatment (e.g., Juarascio et al., 2013; Merwin et al., 2013; Merwin et al., 2019; Timko et al., 2015; Wildes \& Marcus, 2011), but has not previously been leveraged to prevent further progression to an ED.

This paper introduces the AcceptME program, a gamified digital prevention based on ACT, where females at-risk for developing an ED learn how to alter their relationship to thoughts/feelings about eating and body weight and shape concerns and align behaviour with personal values. This is the first study to apply an ACT-based prevention program for ED, delivered digitally and utilizing gamification principles. Further, this is the first program to utilize a third-person perspective, employing prosocial principles (i.e., helping another person deal with their difficulties; Rennie et al., 2016) as a way to learn vicariously from experience and encourage behaviour change. The aim of this study is to describe the development of the AcceptME program, report on its feasibility and acceptability, and summarize participants' feedback to identify the most useful components of this approach.

\section{Methods}




\subsection{Participants}

Participants were recruited from twenty-five public high schools and the University of XXX. Over 1000 young women were screened: 750 high-school students and 306 university students, aged 13 to 25 years $(M=16.80$ years, $S D=2.80)$ (see CONSORT diagram Fig. 1 ). A total of 92 individuals were randomized to the AcceptME group $\left(N=62, M_{\text {age }}=15.27\right.$ years, $\left.S D=2.26\right)$ or the wait-list control group $(N=30$, $M_{\text {age }}=15.09$ years, $\left.S D=1.89\right)$. The majority of the sample (98\%) were Greek-Cypriot; $1 \%$ were TurkishCypriot, and 1\% Maronite. To be included in the study, individuals had to be females aged 13-25 years, voluntarily agree to participate (with parental consent if under 18 years old), have good working knowledge of the Greek language and score 52 or greater on the Weight Concern Scale (WCS, Killen et al., 1996) indicating that they were at-risk for developing ED within 4 years (40). Individuals were excluded if they were identified as possibly having an ED diagnosis based on their Eating Diagnostic Scale score.

\subsection{Procedure}

This study was part of a larger randomized controlled trial (registered at clinicaltrials.org) comparing the experimental intervention to a waitlist control. The screening questionnaire was administered, either manually or via online computer-based administration (using SurveyMonkeyAudience, www.surveymonkey.com/mp/audience) during class time and supervised by project researchers. Screening included the Eating Disorder Diagnostic Scale (EDDS) and students who were identified as having a possible ED diagnosis were referred to the Centre of Prevention and Treatment of Eating Disorders- Children and Adolescents Mental Health Services (only clinic in Cyprus offering these services). Students who met criteria for participation (and their parents if $<18$ years of age) were contacted via telephone and invited to participate in the prevention program. Of those invited, 92 agreed to participate and were randomized to either the AcceptME prevention program $(N=62)$ or a wait-list $(N=$ 30) using random.com with ratio 2:1 with overassignment to the treatment group due to high rates of drop out previously reported with digital interventions (Macea et al., 2010). Individuals randomized to the AcceptME condition were sent a text message with webpage link, username, and password. AcceptME participants completed assessments at baseline, after each session, post-intervention (immediately after completing Session 6) and at 1-month post-intervention follow-up.

The local National Bioethics Committee and the Ministry of Education approved the study. All participants (and their parents if underage) completed informed consent prior to participation.

\subsection{Digital protocol and software development}

A website was developed to host the program. The software development used PHP (php.net) and Jquery (jquery.com). The Backend code was developed in Symphony (symphony.com). Graphics were created using "Gif animations". Character voices were recorded using "garage band" application.

The digital prevention program consisted of 6 sessions and each session had to be completed within the same day it was began (i.e., the participant could not return to the session at a later time). Sessions were 
consecutive and participants had to complete them in order. Between sessions, participants received one text message three days after their last login inviting them to complete the next session.

The storyline (narrative) chosen for the prevention program was a story of a young girl contemplating whether to enter a reality television fashion contest. The participant followed the main character through the storyline as she made the decision to enter the contest and faced situations that elicited difficult thoughts and emotions, generally and specifically related to her body. A third person perspective was used, where the participant viewed the events unfolding from the perspective of an observer. The participants were encouraged to assist the leading character in progressing in the game by completing exercises that taught ACT skills (e.g., acceptance, defusion, present moment awareness) to cope with distressing thoughts/feelings. Participants' responses to various exercises were integrated into later conversations between the leading character and other characters in the "game," providing some tailoring of the storyline to help the participant identify with the leading character and her challenges. The participant was also asked to help the character overcome some difficulties, for example by providing advice on how to handle difficult situations or by giving suggestions on what ACT skills to use to manage a specific problem or difficulty later in the program. By asking the participant to help the character achieve her goals, the aim was for participants to gain new skills that could be applied to their own life (see https://www.youtube.com/watch?v=VapfyrqeNmM for a video run-through of sessions).

Each of the six sessions included ACT experiential exercises and metaphors to teach core skills. The choice of experiential exercises and metaphors were based on ease of adaptation to an interactive, digital format (without a face-to-face encounter) and integration into the storyline; and fit to the target population (i.e., developmentally appropriate and well-matched to young women). Additional gamification components included awarding of points upon completion of sessions, exercises and homework; animations, videos, and interactive exercises.

The prevention program protocol borrowed from different ACT resources, manuals and self-help books for ED (Ciarrochi, Hayes, \& Bailey, 2012; Heffner et al., 2002; Pearson et al., 2012; Lillis, Dahl \& Weineland, 2014) and previous ACT-based digital interventions (Karekla \& Savvides, 2019; Karekla et al., 2021). Sessions were approximately 30 minutes in duration. Table 1 outlines session content, goals and interventions.

\subsection{Measures}

Participants completed a demographics questionnaire (e.g., age, nationality, year in school), as well as the EDDS and the WCS at baseline. They completed measures of acceptability at the end of each session and program satisfaction at the end of the study (1-month follow up). Additional measures were administered at baseline, end-of-treatment and 1-month follow-up; however, these measures are not included in the current manuscript which focuses on program acceptability and feasibility.

The Eating Disorder Diagnostic Scale (EDDS; Stice et al., 2000) is a 22-item self-report scale of ED symptoms. The diagnostic items are summed forming an overall composite indicating ED symptom 
severity. The EDDS has shown high agreement with diagnoses made with the Eating Disorder Examination (EDE; Fairburn et al., 1995) and is used to identify individuals meeting ED diagnosis criteria. The scale was found to have high test-retest reliability ( $r=.87$, Stice et al., 2000) and adequate reliability in the present study (Cronbach's alpha $=.62$ ).

The Weight Concerns Scale (WCS; Killen et al., 1996) consists of 5 questions assessing fear of weight gain, worry about weight and body shape, importance of weight, diet history, and perceived fatness. The WCS (scores above 52) is found to identify individuals at risk for the later development (within the next 4 years) of disordered eating (40). Previous studies (40) reported satisfactory internal consistency (Cronbach's alpha > .70) and in the present study Cronbach's alpha $=.76$.

End-of-Session Questionnaire. At the end of every session, participants completed a questionnaire assessing satisfaction and perceived usefulness of each treatment session and its interventions, including whether the session was helpful in meeting its stated goals, and which aspects participants found the most or least useful (more than one choice was allowed). Items were rated on a Likert scale ranging from $0=$ Not at all helpful to $10=$ Extremely helpful.

The Program Satisfaction Questionnaire (PSQ; adapted from Gulec et al., 2011; see Supplementary materials) was administered at end of study participation. Items were added or adapted to match the AcceptME program content and intentions of this program.

\section{Results}

\subsection{Attrition}

Seventeen of the 48 participants who started the AcceptME program dropped out before Session 6, for an attrition rate of $35.42 \%$. Post-intervention data were obtained on $97 \%(N=30)$ of treatment completers, and follow-up data was obtained on $81 \%(N=25)$. Two participants were unable to complete assessments due to technical problems (their data could not be saved on the server and after two attempts they were not willing to answer the questions again). Participants who did not log into the program were contacted to review discontinuation reasons and all reported that it was a matter of lack of time (due to upcoming school exams). A few faced technical difficulties (the program did not save their work so they would have to redo the session) and that discouraged continuation; or they had trouble with slow internet connection making it unfeasible to run the program from home.

\subsection{Reasons for participating in AcceptME}

The most common reason given for participating in the program was the opportunity to get expert advice $(N=17)$ followed by curiosity about the program and online help $(N=7)$, anonymity offered $(N=6)$, receiving free services $(N=5)$ without the need to go anywhere themselves $(N=2)$, and possibility of continuous support whenever needed $(N=2)$.

\subsection{Participant feedback on sessions}


Table 1 summarizes session content and participant feedback on session goals and interventions.

\subsection{Program satisfaction}

The majority of the participants reported being satisfied (57\% Mostly Satisfied, $40 \%$ Very Satisfied). A small percentage was Mildly Dissatisfied (3\%). Most participants perceived the quality of the program to be excellent to good ( $47 \%$ Excellent, $40 \%$ Good, $13 \%$ Fair). The majority of the participants reported that the program helped them deal more effectively with their body-related thoughts and worries $(52 \%$ Helped a lot, $48 \%$ Helped a bit). About half (47\%) of the participants reported that if they were to seek help again, they would return to this program and that they would recommend the program to a friend who might want to receive similar help.

The vast majority of participants reported that they learned something new from the program (92\%) and that, overall, their participation was helpful (82\%). All participants reported utilizing the techniques they learned, at least a little (40\% A lot, $52 \%$ Somewhat and $8 \% \mathrm{~A}$ little). Forty-seven percent of participants thought that they would have been worse, $40 \%$ the same, $13 \%$ better during the past 4 months in regard to their body-related difficulties if they did not participate in the program. The aspects of the program that participants identified as most helpful were: learning how to apply acceptance techniques to manage body related thoughts ( $48 \%$ of participants) and identifying their values and goals ( $48 \%$ of participants), learning techniques to get "unstuck" from thoughts (32\% of participants), realizing when they get stuck with thoughts ( $28 \%$ of participants), how to apply acceptance techniques to manage body related emotions ( $24 \%$ of participants), feeling as though they were helping the main character ( $16 \%$ of participants) and the mindfulness exercises ( $8 \%$ of participants).

When asked specifically about program duration, $45 \%$ participants reported that the duration of the program was appropriate and $29 \%$ reported it was too long. Participant critical comments for future program improvement were: Sessions took too long to complete and preference for shorter sessions; Wish to be able to pause or stop the videos any time and be able to return to them later; and Would have liked to have additional such online programs for other issues (e.g., stress). Positive comments included: The program was really helpful; There was nothing they did not like, and Really enjoyed participating.

All data is available from the authors upon request.

\section{Discussion}

This is the first study to apply an ACT-based selective prevention program for ED, delivered in a digital modality, utilizing gamification principles and a third-person perspective for intervention delivery. Overall, the program was acceptable and feasible for women and girls at-risk for developing an ED, and reportedly useful for dealing with body-related concerns.

The program components most commonly identified by participants as helpful were: 1) learning to apply acceptance techniques to manage body-related thoughts and 2) clarifying values (each identified by $48 \%$ of participants). Relatively fewer identified learning acceptance of body-related emotions as helpful 
(24\%). In terms of specific interventions, the vast majority of participants identified the values interventions as helpful. The fewest participants identified the mindfulness exercise as helpful (only 8\%), indicating that this might be less palatable or useful to this population or in this format, or that there was not enough emphasis on this component in the current program for it to be useful. The session focused on identifying behaviors the individual engages in to avoid body-related thoughts/feelings and discovering how these behaviors are unworkable in the long run, received the lowest average rating of helpfulness (although still rated as "Somewhat" to "Very Helpful"). This suggests that this session may be targeted for improvement in a future iteration of this program.

ACT intends to help individuals choose their behaviours based on personal values. Values clarification serves multiple purposes in ACT as it increases willingness to allow difficult thoughts and feelings to occur and provides an organizational framework for behavioural changes (49); it is also proposed to function as a positive reinforcer for the therapeutic interventions, especially when the short-term consequences (e.g., discomfort) are unpleasant (Wilson \& Murrell, 2004). A strong motivation is needed to relinquish emotional control strategies that provide short-term relief, even when these strategies limit behavioural repertoires (44). In order to increase motivation for engagement and participation in the AcceptME program, values work began early in the intervention and continued throughout with explicit links between values and the techniques that were taught, thus providing meaning for any behavioural changes proposed. Working on values clarification from the first session gave an opportunity for the participants to imagine the life they would like to have, and how they could expand their lives to encompass much more than body-related goals (44). This is somewhat of a departure from previous ACT manuals for dealing with eating-related difficulties $(43,51)$ which present values work towards the end of therapy, and may address a key deficit in this population. Further research is needed to determine whether participants' engagement is greater when values work is introduced in the initial versus later intervention sessions, and how it can be further leveraged to decrease attrition common in digitalized programs.

Other factors that played a role in engagement with the program included the opportunity to get expert advice, curiosity, and the anonymity this modality presents. As expected, participants enjoyed and found useful the gamification processes adopted in this program. Further the idea of vicarious learning from the characters within the game appeared to be effective as participants reported that they learned acceptance, defusion and valued-living skills. Vicarious learning stemming from Banduras' social cognitive theory (52) is a longstanding and effective means of achieving behavior change. It remains to be further explored however whether a first vs. third perspective viewpoint within gamification is more effective for eating related behaviour change. For instance, Rennie and colleagues (2016) supported that visualizing the behaviour from a third person perspective increases intention to perform that behaviour, but only if the behaviour is relatively easy to perform. A digital prevention program that would offer the option to choose between first- and third-person perspective for different tasks would provide further information on which viewpoint is most effective.

Participants feedback regarding drawbacks of the program included the length of the program (both the time needed to complete each session and the number of sessions), the repetition of questionnaires, and 
inability to pause the sessions, requiring participants to complete each session in its entirety at once. Also, due to the programs' digital requirements (high speed internet and updated browser in order to be able to "run") some technical difficulties arose, which precluded some individuals from participating. Future digital program development should address these problems. It was useful that the program could run on smart mobile phones, as some of the participants did not have access to a computer.

High attrition rates plague digital prevention programs for psychological health, with 1 in 4 individuals found to dropout from digital prevention and intervention programs for disordered eating (Linardon, Messer \& Fuller-Tyszkiewicz, 2020). Wade \& Wilksch (2018) argued that low dropout rates reported in some studies are evident if only university students are included vs. higher rates if community and adolescent samples are included. Dropout rate was similar in this study, with overall attrition from pre to post being $35.42 \%$. Most participants who dropped out did so early (before beginning the treatment, i.e., pre-Session 1). The pre-intervention assessment may have contributed. Thus, modifications, such as decreasing assessment time may engage participants and reduce early dropout. Providing a trailer or snapshot of the program may also be helpful, and relatability to the storyline and the characters may also be explored to increase engagement and impact (Karekla et al., 2019; Yardley et al., 2016).

Limitations of this study include the broad age range which may have limited tailoring of the content and exercises for adolescents versus young adults. This study did not examine the effectiveness of the intervention but was mainly concerned with the acceptability and feasibility of this gamified approach to body weight and shape-related concerns among young women and girls. A randomized clinical trial with longer term follow-up is necessary to examine the impact of the intervention on risk for developing eating disorders.

\section{Conclusions}

In conclusion, results suggest that for this group of individuals, the AcceptME program was acceptable and perceived as a helpful intervention to deal with body-related thoughts and worries. Feedback indicates that the delivery of digital prevention programs with gamification processes is promising. Gamification processes present with many advantages that can be used in conjunction with behaviour change knowledge to produce effective digital programs. As young people use and rely more on new technologies, theory-driven game-based prevention programs will continue to revolutionize the field of prevention especially for hard-to-reach youth.

\section{Abbreviations}

ACT: Acceptance and Commitment Therapy

ED: Eating Disorders

EDDS: Eating Disorder Diagnostic Scale

WCS: Weight Concerns Scale 
PSQ: Program Satisfaction Questionnaire

\section{Declarations}

Ethics approval and consent to participate: The Cyprus National Bioethics Committee (EEBK/ $\mathrm{E} / 2013 / 05$ ) and the Ministry of Education approved the study. All participants (and their parents if underage) completed informed consent prior to participation.

Availability of data and materials: Data and materials are available from the authors upon request.

Consent for publication: No individual person's data is presented and as such no such consent is required. All participants signed an informed consent prior to participation which also informed them that the findings of the study will be published.

Availability of data and materials: All data and materials are not yet publicly available until all aspects of the study (i.e. randomized clinical trial) are complete. However, they are available from the corresponding author upon request.

Competing interests: All authors declare no competing interests.

Funding: This research did not receive any specific grant from funding agencies in the public, commercial, or not-for-profit sectors. Money from the last authors' research allowance and start-up funding were used.

Authors' contributions: This study constituted part of the doctoral dissertation project of PN under the supervision of MK. PN and MK conceptualized the study, developed the program, run the study and authored the manuscript. RM helped with the development of the ACT intervention for eating disorders and in writing the manuscript. All authors read and approved the final manuscript.

\section{References}

1. Forrest LN, Smith AR, Swanson SA. Characteristics of seeking treatment among U.S. adolescents with eating disorders. Int J Eat Disord. 2017;50(7):826-33.

2. Ali K, Farrer L, Fassnacht DB, Gulliver A, Bauer S, Griffiths KM. Perceived barriers and facilitators towards help-seeking for eating disorders: A systematic review. Int J Eat Disord. 2017;50(1):9-21.

3. Newton MS, Ciliska D. Internet-based innovations for the prevention of eating disorders: A systematic review. Eat Disord. 2006;14(5):365-84.

4. Karekla M, Savvides SN. Smoking cessation avatar-led Acceptance and Commitment Therapy digital intervention: feasibility and acceptability in young adults. Transl Behav Med. 2019; 
5. Kahn J, Ducharme P, Rotenberg A, Gonzalez-Heydrich J. "RAGE-Control”: A Game to Build Emotional Strength. Games Health J. 2013;2(1):53-7.

6. Deterding S, Dixon D, Khaled R, Nacke L. From game design elements to gamefulness: Defining "gamification." Proc 15th Int Acad MindTrek Conf Envisioning Futur Media Environ MindTrek 2011. 2011; (March 2014):9-15.

7. Lieberman DA. What can we learn from playing interactive games? Playing Video Games: Motives, Responses, and Consequences. 2006. p. 447-69.

8. Anderson J, Chung YC, Macleroy V. Creative and critical approaches to language learning and digital technology: findings from a multilingual digital storytelling project. Lang Educ [Internet]. 2018;32(3):195211. Available from: https://doi.org/10.1080/09500782.2018.1430151

9. Mayes T, Dineen F, Mckendree J, Lee J. Learning from watching others learn 1 . 1 The Vicarious Learner Project. Learning. 2001;1-16.

10. Negrete A, Lartigue C. Learning from education to communicate science as a good story. Endeavour. 2004;28(3):120-4.

11. Karekla M, Kasinopoulos O, Neto DD, Ebert DD, Van Daele T, Nordgreen T, et al. Best Practices and Recommendations for Digital Interventions to Improve Engagement and Adherence in Chronic Illness Sufferers. Eur Psychol. 2019;24(1).

12. Pappas BC. 6 Benefits Of Vicarious Learning In eLearning Courses [Internet]. 2015 [cited 2021 Jul 4]. p. 1-6. Available from: https://elearningindustry.com/6-benefits-of-vicarious-learning-in-elearning-courses

13. Rennie LJ, Harris PR, Webb TL. Visualizing actions from a third-person perspective: effects on health behavior and the moderating role of behavior difficulty. J Appl Soc Psychol. 2016;46(12):724-31.

14. Hagger MS, Lonsdale A, Chatzisarantis NLD. Effectiveness of a brief intervention using mental simulations in reducing alcohol consumption in corporate employees. Psychol Heal Med. 2011;16(4):375-92.

15. Johnson D, Deterding S, Kuhn KA, Staneva A, Stoyanov S, Hides L. Gamification for health and wellbeing: A systematic review of the literature. Internet Interv [Internet]. 2016;6:89-106. Available from: http://dx.doi.org/10.1016/j.invent.2016.10.002

16. Loucas CE, Fairburn CG, Whittington C, Pennant ME, Stockton S, Kendall T. E-therapy in the treatment and prevention of eating disorders: A systematic review and meta-analysis. Behav Res Ther [Internet]. 2014;63(2014):122-31. Available from: http://dx.doi.org/10.1016/j.brat.2014.09.011

17. Stice $E$, Becker $C B$, Yokum S. Eating disorder prevention: Current evidence-base and future directions. Int J Eat Disord. 2013;46(5):478-85. 
18. Stice E, Marti CN, Shaw H, Rohde P. Meta-analytic review of dissonance-based eating disorder prevention programs: Intervention, participant, and facilitator features that predict larger effects. Clin Psychol Rev [Internet]. 2019;70(February 2018):91-107. Available from: https://doi.org/10.1016/j.cpr.2019.04.004

19. Vanderlinden J. Many roads lead to Rome: Why does cognitive behavioural therapy remain unsuccessful for many eating disorder patients? Eur Eat Disord Rev. 2008;16(5):329-33.

20. Hayes SC, Strosahl KD, Wilson KG. Acceptance and commitment therapy: The process and practice of mindful change, 2nd ed. Acceptance and commitment therapy: The process and practice of mindful change, 2nd ed. New York, NY, US: Guilford Press; 2012. xiv, 402-xiv, 402.

21. Cockell SJ, Zaitsoff SL, Geller J. Maintaining change following eating disorder treatment. Prof Psychol Res Pract. 2004;35(5):527-34.

22. Heatherton TF, Baumeister RF. Binge eating as escape from self-awareness. Psychol Bull. 1991;110(1):86-108.

23. Koushiou M, Nicolaou K, Karekla M. Inducing negative affect using film clips with general and eating disorder-related content. Eat Weight Disord. 2018;

24. Merwin RM, Timko CA, Moskovich AA, Ingle KK, Bulik CM, Zucker NL. Psychological inflexibility and Symptom Expression in Anorexia Nervosa. Eat Disord. 2011;19(1):62-82.

25. Merwin RM, Moskovich AA, Wagner HR, Ritschel LA, Craighead LW, Zucker NL. Emotion regulation difficulties in anorexia nervosa: Relationship to self-perceived sensory sensitivity. Cogn Emot. 2013;27(3):441-52.

26. Levin ME, Luoma JB, Haeger JA. Decoupling as a Mechanism of Change in Mindfulness and Acceptance: A Literature Review. Behav Modif. 2015;39(6):870-911.

27. Juarascio A, Shaw J, Forman E, Timko CA, Herbert J, Butryn M, et al. Acceptance and Commitment Therapy as a Novel Treatment for Eating Disorders: An Initial Test of Efficacy and Mediation. Behav Modif. 2013;37(4):459-89.

28. Merwin, Rhonda M. \& Wilson K. Understanding and Treating Eating Disorders: An ACT perspective. In: Blackledge, J.T., Ciarrochi, J. \& DFP, editor. Acceptance and commitment therapy: Contemporary theory, research, and practice. Sydney: Australian Academic Press; 2009. p. 87-117.

29. Hayes, S.C., Strosahl, K., \& Wilson K. Hayes, Strosahl, \& Wilson, 1999. New York, NY, US: Guilford Press; 1999.

30. Sandoz EK, Wilson KG, Merwin RM, Kate Kellum K. Assessment of body image flexibility: The Body Image-Acceptance and Action Questionnaire. J Context Behav Sci [Internet]. 2013;2(1-2):39-48. 
Available from: http://dx.doi.org/10.1016/j.jcbs.2013.03.002

31. Ferreira C, Pinto-Gouveia J, Duarte C. The validation of the body image acceptance and action questionnaire: Exploring the moderator effect of acceptance on disordered eating. Int J Psychol Psychol Ther. 2011;11(3):327-45.

32. Manlick CF, Cochran S V., Koon J. Acceptance and commitment therapy for eating disorders: Rationale and literature review. J Contemp Psychother. 2013;43(2):115-22.

33. Pellizzer ML, Waller G, Wade TD. Body image flexibility: A predictor and moderator of outcome in transdiagnostic outpatient eating disorder treatment. Int J Eat Disord. 2018;51(4):368-72.

34. Rogers CB, Webb JB, Jafari N. A systematic review of the roles of body image flexibility as correlate, moderator, mediator, and in intervention science (2011-2018). Body Image [Internet]. 2018;27:43-60. Available from: https://doi.org/10.1016/j.bodyim.2018.08.003

35. Fairburn CG, Cooper Z, Doll HA, O'Connor ME, Palmer RL, Dalle Grave R. Enhanced cognitive behaviour therapy for adults with anorexia nervosa: A UK-Italy study. Behav Res Ther [Internet]. 2013;51(1):R2-8. Available from: http://dx.doi.org/10.1016/j.brat.2012.09.010

36. Merwin RM, Zucker NL, Timko CA. A Pilot Study of an Acceptance-Based Separated Family Treatment for Adolescent Anorexia Nervosa. Cogn Behav Pract [Internet]. 2013;20(4):485-500. Available from: http://dx.doi.org/10.1016/j.cbpra.2012.11.001

37. Merwin RM, Zucker NL, Wilson KG. ACT for anorexia nervosa: A guide for clinicians. ACT for anorexia nervosa: A guide for clinicians. New York, NY, US: The Guilford Press; 2019. x, 286-x, 286.

38. Timko CA, Zucker NL, Herbert JD, Rodriguez D, Merwin RM. An open trial of Acceptance-based Separated Family Treatment (ASFT) for adolescents with anorexia nervosa. Behav Res Ther [Internet]. 2015;69:63-74. Available from: http://dx.doi.org/10.1016/j.brat.2015.03.011

39. Wildes JE, Marcus MD. Development of emotion acceptance behavior therapy for anorexia nervosa: A case series. Int J Eat Disord. 2011;44(5):421-7.

40. Killen JD, Hayward CH, Haydel F, Wilson D, Hammer L, Kraemer H, et al. Weight concerns influence the development of eating disorders. Vol. 64, Journal of Consulting and Clinical Psychology. 1996. p. 93640.

41. MacEa DD, Gajos K, Daglia Calil YA, Fregni F. The efficacy of web-based cognitive behavioral interventions for chronic pain: A systematic review and meta-analysis. J Pain [Internet]. 2010;11(10):91729. Available from: http://dx.doi.org/10.1016/j.jpain.2010.06.005

42. Ciarrochi, Joseph, Hayes, Louise, \& Bailey A. Get Out of Your Mind and Into Your Life for Teens. New Harbinger Publications; 2012. 
43. Heffner M, Sperry J, Eifert GH, Detweiler M. Acceptance and Commitment Therapy in the treatment of an adolescent female with anorexia nervosa: A case example. Cogn Behav Pract. 2002;9(3):232-6.

44. Pearson AN, Follette VM, Hayes SC. A Pilot Study of Acceptance and Commitment Therapy as a Workshop Intervention for Body Dissatisfaction and Disordered Eating Attitudes. Cogn Behav Pract [Internet]. 2012;19(1):181-97. Available from: http://dx.doi.org/10.1016/j.cbpra.2011.03.001

45. Lillis, J, Dahl, J., \& Weineland SM. The Diet Trap: Feed Your Psychological Needs \& End the Weight Loss Struggle Using Acceptance and Commitment Therapy. [Internet]. Vol. 30, Consumer Connections. New Harbinger Publications; 2014. 1 p. Available from: https://search.ebscohost.com/login.aspx? direct=true $\& \mathrm{db}=\mathrm{ccm} \& A N=97070673 \&$ site=ehost-live\%0Ahttps://search.ebscohost.com/login.aspx? direct $=$ true $\& d b=c c m \& A N=103975506 \&$ site $=$ ehost-live

46. Karekla M, Savvides SN, Gloster A. An avatar-led intervention promotes smoking cessation in young adults: A pilot randomized clinical trial. Ann Behav Med. 2021;54(10):747-60.

47. Stice E, Telch CF, Rizvi SL. Development and validation of the eating disorder diagnostic scale: A brief self-report measure of anorexia, bulimia, and binge-eating disorder. Psychol Assess. 2000;12(2):123-31.

48. Gulec H, Moessner M, Mezei A, Kohls E, Túry F, Bauer S. Internet-based maintenance treatment for patients with eating disorders. Prof Psychol Res Pract. 2011;42(6):479-86.

49. Wersebe H, Lieb R, Meyer AH, Hoyer J, Wittchen HU, Gloster AT. Changes of valued behaviors and functioning during an Acceptance and Commitment Therapy Intervention. J Context Behav Sci [Internet]. 2017;6(1):63-70. Available from: http://dx.doi.org/10.1016/j.jcbs.2016.11.005

50. Wilson, K.G. \& Murrell A. Values Work in Acceptance and Commitment Therapy. In 2004. p. 283.

51. Berman MI, Boutelle KN, Crow SJ. A case series investigating acceptance and commitment therapy as a treatment for previously treated, unremitted patients with anorexia nervosa. Eur Eat Disord Rev. 2009;17(6):426-34.

52. Bandura. 140969065[6024].Pdf. Annu Rev Psychol. 2001;52:1-26.

53. Linardon, Shatte J., Messer, Firth M., Fuller-Tyszkiewicz M. (/)(https://www.apa.org). J Consult Clin Psychol. 2020;88(11):994-1007.

54. Wade TD, Wilksch SM. Internet eating disorder prevention. Curr Opin Psychiatry. 2018;31(6):456-61.

55. Yardley L, Spring BJ, Riper H, Morrison LG, Crane DH, Curtis K, et al. Understanding and Promoting Effective Engagement With Digital Behavior Change Interventions. Am J Prev Med [Internet]. 2016;51(5):833-42. Available from: http://dx.doi.org/10.1016/j.amepre.2016.06.015

\section{Tables}


Table 1 Sessions content, goals, intervention components presented and perceived helpfulness 
Session $1(n=48)$

Description: Introduced the characters and storyline, and presented an overview of the program.

Primary Goals

How helpful was this session in...

0 (Not at all)-10 (Extremely)

Scale

Discovering how our body-related thoughts affect our life

$M=7.94, S D=1.45$

Clarifying our values in life ${ }^{1}$

$M=8.30, S D=1.33$

Intervention components presented

Which activity was most helpful?

Which activity was NOT helpful?*

NIdentifying as "Most Helpful"/

"Not helpful", \% of active

participants identifying as

helpful

The question: How would your life be different if you did not

allow negative thoughts about your body to guide you?

$45 / 10,94 \%$

The question: How different would your life be if you were not constantly on a diet? What would you spend your energy on?

Values-Game of Life ${ }^{2}$

$30 / 30,63 \%$

Life Map exercise ${ }^{3}$

$30 / 0,63 \%$

Session $2(n=41)$

Description: Aimed to undermine experiential avoidance via experiencing ones' own struggle with thoughts/feelings (adapted from Pearson et al., 2010; Lillis et al., 2014) and identifying control/avoidance strategies used to manage distressing thoughts and feelings, and examining the workability of these strategies. Ineffectiveness of changing internal experiences by changing something external (e.g., body weight and shape) was demonstrated (Pearson et al., 2010) and the concept of cognitive defusion as an alternative was introduced.

Primary Goals

How helpful was this session in...

0 (Not at all)-10 (Extremely)

Scale

Discovering the behaviours you engage in, in order to change

$M=6.94, S D=1.78$

thoughts and feelings about your body

Discovering that the control/avoidant behaviours are not helpful in the long-run

Intervention components presented

$M=6.69, S D=1.95$

Which activity was most helpful? Which activity was NOT helpful?*

NIdentifying as "Most Helpful"/

"Not helpful", \% of active 


\section{Avatar discussions regarding control/avoidant behaviours and $\quad 11 / 6,27 \%$ chocolate cake metaphor}

Discussion of avatar with other characters about worrisome

$11 / 3,27 \%$ body-related thoughts \& feeling (demonstrating fusion with thoughts)

Writing a list of all the things you have tried to make your thoughts and feeling change or go away

Open-ended question exercise to connect with personal struggle $\quad 10 / 2,24 \%$ with thoughts and feelings 5

Distancing exercise ${ }^{6}$

$10 / 6,24 \%$

Discussion of avatar with other characters about the ABCs of $\quad 9 / 6,22 \%$ behavior (Antecedents, Behavior, Consequences)

Ball in the pool metaphor ${ }^{7}$

$8 / 6,20 \%$

Session $3(n=37)$

Description: This session focused on identifying additional experiential avoidance behaviors related to difficult thoughts and to introduce willingness and acceptance as alternatives to control.

Mindfulness is presented as a technique to help become more aware of thoughts and emotions in the present.

Primary Goals

How helpful was this session in...

0 (Not at all)-10 (Extremely)

Scale

Learning to recognize feelings

Learning acceptance and mindfulness

Intervention components presented
$M=8.17, S D=1.42$

$M=8.06, S D=1.50$

Which activity was most helpful? Which activity was NOT helpful?*

NIdentifying as "Most Helpful"/

"Not helpful", \% of active participants identifying as helpful

$16 / 13,43 \%$

Exercise to identify different emotions and open-ended questions for emotional awareness and identification of control/avoidance behaviours related to each emotional state.

Rip Current Metaphor ${ }^{8}$

$21 / 9,57 \%$

Tug of War with a Monster metaphor ${ }^{9}$

$19 / 15,51 \%$

Mindfulness training

$21 / 9,57 \%$ 
Exposure exercise facing fears

Helping Selena (main character) with her fears- practicing mindfulness and acceptance skills
$20 / 13,54 \%$

$20 / 13,54 \%$

Session $4(n=33)$

Description: This session aimed at identifying additional behaviours used to manage difficult thoughts and to elaborate on cognitive defusion. It also made a distinction between observing vs. thinking-self.

Primary Goals
How helpful was this session in...

0 (Not at all)-10 (Extremely)

Scale

Helpful in discovering their body related thoughts/judgments

Learning techniques to get unstuck from their thoughts

Intervention components presented

Mindfulness Mirror exposure exercise ${ }^{10}$

Thought defusion Musical thoughts exercise ${ }^{11}$

Thought defusion Cartoon voice exercise ${ }^{12}$

Thought parade exercise ${ }^{13}$

Mind as a trash can metaphor ${ }^{14}$

Avatar encouraging the participant to engage in the Mirror exposure and cognitive defusion exercises presented in this session

Session $5(n=32)$

Description: The goal of this session was to further clarify values in regards to relationships and integrate techniques learned in previous sessions to manage a difficult emotional situation. This session aimed to assist with generalization of skills learned to other life situations.

Primary Goals

How helpful was this session in...

0 (Not at all)-10 (Extremely)

Scale

Clarifying relationship values

$M=8.68, S D=1.68$

Intervention components presented 
Discussion \& questions clarifying relationship values ${ }^{15}$

Avatar encouraging the participant to engage in an exercise exploring how they would like to act in relationships ${ }^{15}$
$26 / 7,81 \%$

$23 / 7,72 \%$

\section{Session $6(n=31)$}

Description: This session focused on termination and continued practice following the end of the gamified intervention. It integrated the importance of willingness to experience thoughts and feelings, highlighting choices in the present moment and pivoting towards choosing to act in accordance to ones' values. The game ended with a summary and review of all skills learned in this program.

Primary Goals

How helpful was this session in...

0 (Not at all)-10 (Extremely) Scale

Evaluation of values-based living

$M=8.58, S D=1.66$

Intervention components presented

Demons in the purse metaphor ${ }^{16}$

Revisiting the Life map created in session 1 and planning for values-based behaviors for the future (committed action)

Open-ended questions ${ }^{17}$ for goal setting, identifying obstacles and planning for utilizing skills learned to overcome barriers to values-based actions

Note: *more than one choice was allowed.

** For session 6, participants were not asked to which components they found most helpful as session 6 comprised mostly of reviewing and summarizing previously presented concepts.

${ }^{1}$ Values clarification (Hayes, Strosahl \& Wilson, 2011): Involves first clarification of deeply meaningful chosen values as opposed to confusion about what is meaningful for the person, and secondly living life congruently to what is really important for the person (i.e., behaving in accordance to one's values).

${ }^{2}$ Values-Game of life: This is a game adapted and digitized originally from Hayes \& Ciarrochi (2015) (see also, Karekla et al., 2020). It involves playing a game where the person first chooses 5 numbers randomly from 0-60 and then being informed that these numbers correspond to how their life would unfold.

Participants are asked to consider whether this is indeed how they would like their life be and proceed with making their values choices from a table of 60 values statements about how they would like their life to be about. In this program, the avatar is playing the game with the help of the participant. 
${ }^{3}$ Life Map exercise: This exercise follows the values clarification Game of life and participants are asked to design for themselves a map of how they would like their life to be (see Figure 2, panels $2 \& 3$ ). This map looks like a city map with different neighborhoods each representing different values areas based on choices made above. In this program, the avatar creates this map with the help of the participant thus reflects the participant choices.

${ }^{4}$ Chocolate cake metaphor (Hayes et al., 1999): This metaphor demonstrates the inevitability of control of thoughts and the thought suppression paradox. It involves asking the person to not think about a chocolate cake whilst the presenting avatar describes a cake in detail.

${ }^{5}$ Exercise to identify personal struggle with control and avoidance of thought and emotion strategies (adapted from Pearson et al., 2010; Lillis et al., 2014).

${ }^{6}$ Distancing exercise (Harris, 2009): This exercise introduces the concept of cognitive defusion. It demonstrates this concept by having the person explore what they see when their hands cover their eyes and compares this to how thoughts become "stuck" and make it hard for us to see which results in struggling to get rid of these thoughts so as to be able to function.

${ }^{7}$ Ball in the pool metaphor (adapted from Pearson et al., 2010): This metaphor parallels the effort one exerts on catching a ball in a pool to struggling with thoughts and emotions and how such struggling results in missing out in engaging with valued living activities.

${ }^{8}$ Rip current metaphor (adapted from Karekla, 2014; Kelly \& Karekla, 2022): This metaphor presents how sometimes listening to what our minds or our emotions tell us (struggling), we may end up getting into more trouble (drawn in a rip current).

${ }^{9}$ Tug of War with a Monster metaphor (adapted from Pearson et al., 2010): This metaphor illustrates willingness to have thoughts and emotions and stop the struggle with them.

${ }^{10}$ Mirror exercise (adapted from Pearson et al., 2010): Mindfulness exposure to distressing thoughts about body shape and size.

${ }^{11}$ Musical thoughts exercise (Harris, 2007): Defusion from thoughts exercise, where the participant is asked to sign their thoughts to for example the music of the "happy birthday" song.

${ }^{12}$ Cartoon voice exercise (Harris, 2007): Defusion from thoughts exercise, where the participant is asked to imagine a favourite cartoon character sign the participant thoughts in the cartoons' voice.

${ }^{13}$ Thought parade exercise (adapted from Lillis et al., 2014): Cognitive defusion exercise where the individual imagines themselves looking at a big stage while large signs featuring each bothersome thought enters and exits the stage (in this case thoughts parade on a catwalk). Selena is presented to 
utilize these exercises to defuse from her judgmental body-shape thoughts and proceeds to carry out a photo shoot task that is of importance to her (values-based action).

${ }^{14}$ Mind as a trash can metaphor (adapted from Karekla, 2014): A self-as-context exercise that aims to develop transcendent self-awareness and assist in the recognition of the observing and thinking-self. This metaphor parallels the mind as a box or a trash can that within it one can find some useful items and some unwanted, ugly or disgusting items, yet attempts to get rid of these unwanted items leads to the addition of more "junk" in the trash-can.

${ }^{15}$ Questions clarifying relationship values (adapted from Ciarrochi et al., 2012): These questions were utilized in the story discussion between the avatar characters and aimed to engage the participant into exploring and clarifying their relationship-related values and then to ponder as to how they would like to act in relationships. The avatar demonstrates putting their choices in action (values-based action) and the participant is encouraged to also take similar actions.

${ }^{16}$ Demons in the purse metaphor (adapted from Lillis et al., 2014): In this metaphor worrisome and distressing thoughts are presented as demons who show up and make noise but who cannot be controlled or gotten rid of. The person is presented with a choice on how to act and the solution presented here is to place the demons in Selenas' purse and carry them with her (demonstrating willingness and acceptance of thoughts and emotions) while she engages in values-based actions (e.g., proceeding in the game).

17Open-ended questions (adapted from Heffner et al, 2002): These questions were used to aid in anticipating obstacles to values-based actions and future action planning.

\section{Figures}




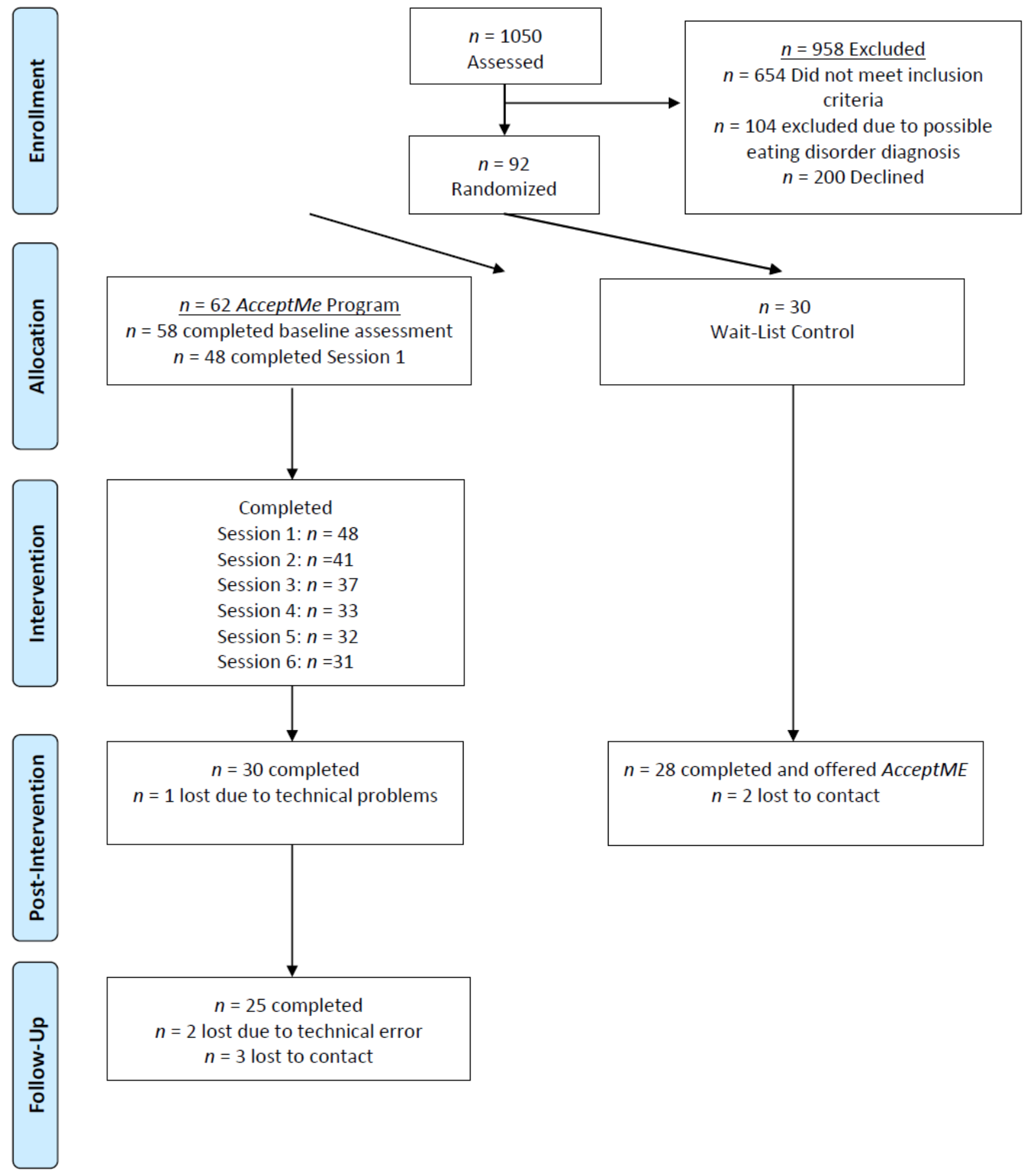

Figure 1

CONSORT flow diagram 

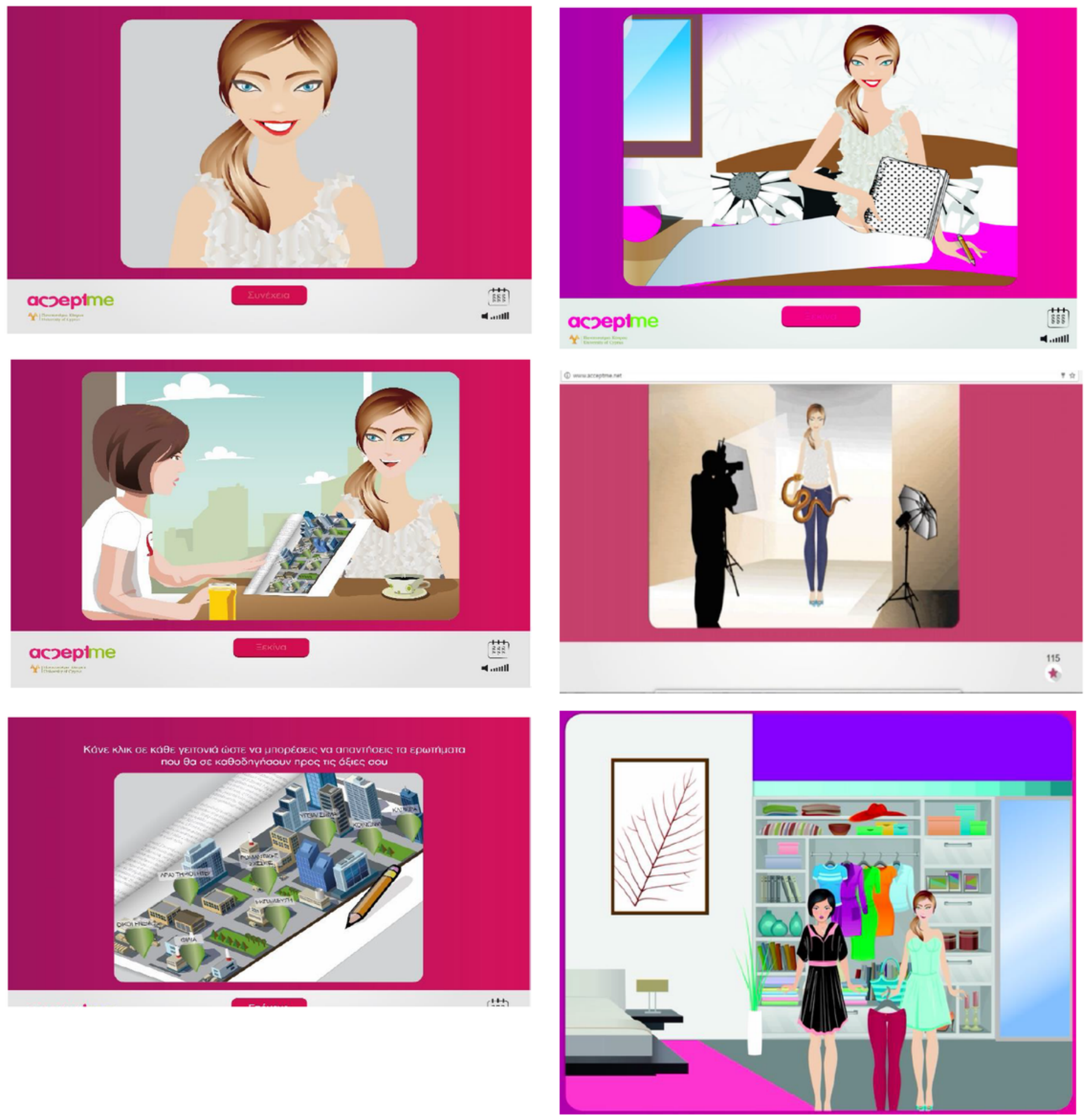

\section{Figure 2}

Pictures from the AcceptME program. In order from the top: (1) Main character, avatar; (2) A scene from session one; (3) Values exercise-Building a values-living map; (4) End of each session-Session recapavatar reciting her learning and achievements in her diary; (5) Illustration of a facing ones' fear exercise; (6) Illustration of avatar receiving rewards (new clothes) for achievements in the program. 


\section{Supplementary Files}

This is a list of supplementary files associated with this preprint. Click to download.

- SuppIMaterialProgramEvaluationQ.doc 